\title{
A RESPONSIBLE PATIENT: FROM THEORY TO PRACTICE ON A MODEL OF A PATIENT WITH BRONCHIAL ASTHMA
}

D0I: $10.36740 /$ WLek202003106

\author{
Valentyna I. Velychko, Yaroslava I. Venher, Daria 0. Lahoda \\ ODESA NATIONAL MEDICAL UNIVERSITY, ODESA, UKRAINE
}

\begin{abstract}
Introduction: The medicine of today is focused on personalized aid to a patient, which involves partnership and mutual responsibility between the patient and the doctor. In our reality, the patient believes that the responsibility for the treatment and outcome depends on the doctor in most cases.

The aim: Induce the patient to develop responsibility for the course of asthma against the background of EBW or obesity and introducing this program into the practice of family physicians.

Materials and methods: By design, the study included 75 patients with asthma with varying degrees of severity, persistent course in the remission stage against the background of EBW or obesity. According to the randomization method, the patients were divided into 3 groups: the main group - 30 patients (the use of medication), the comparison group - 30 patients (training in the "Asthma School"), the $3^{\text {rd }}$ group was controls of 15 patients (basic therapy).

Results: According to the anthropometric study, 75 patients enrolled in the study were found to have EBW or obesity and the mean BMI was $31.67 \pm 0.53 \mathrm{~kg} / \mathrm{m}^{2}$. It was also found that 20 (66.67\%) patients in the main group and $21(70.00 \%)$ patients in the comparison group did not regularly use basic therapy and cancelled or changed the drugs without permission. After the training, 45 patients (76.66\%) of the total patients of the main group and the comparison group began to perform respiratory movements with the inhalation device correctly. patients in the main group reduced body weight on an average by $4.5 \mathrm{~kg}$, and BMI from $32.00 \mathrm{~kg} / \mathrm{m}^{2}$ changed to $29.7 \mathrm{~kg} / \mathrm{m}^{2}(\mathrm{p}<0.05)$, although they did not reach $25.0 \mathrm{~kg} / \mathrm{m}^{2}$ of the target level because the follow-up period was not long.

Conclusion: Only patients in the main group had significant positive changes in asthma control, the patients in the comparison group also had positive dynamics, but it did not show statistically significant differences. The doctor should be interested in the fact that at the first and subsequent visits regarding the disease, in our case it is bronchial asthma, the patient will feel responsible for the disease. Therefore, when communicating with the patient, the physician should focus on this, provide the most complete answers to the patient's questions, provide educational literature and, if necessary, diaries of self-control.
\end{abstract}

KEY WORDS: bronchial asthma, excessive body weight, obesity, responsible patient

Wiad Lek. 2020;73(3):444-448

\section{INTRODUCTION}

The medicine of today is focused on personalized aid to a patient, which involves partnership and mutual responsibility between the patient and the doctor. In our reality, the patient believes that the responsibility for the treatment and outcome depends on the doctor in most cases. This postulate is not objective and does not help to achieve a complete relationship between the patient and the doctor, which in turn impairs the outcome of treatment.

Referring to the urgency of this issue, we can say that when searching for papers and publications on this topic in Ukrainian or Russian, we only received a reference to the Criminal Code, which contains articles on criminal responsibility of doctors or patients. However, there are no data indicating how to encourage the patient to cooperate with the further development of the patient's responsibility for his or her state of health, treatment, etc.

As for the English-language sources, we have a number of publications that do not make its aim to improve our understanding of the patient's responsibility. Thus, one of the first publications on this topic refers to 2003 [1], which states that the future of medicine should be aimed at the formation of an "independent" patient who will have sufficient knowledge about the disease, methods of treatment, etc that he will receive from the doctor and will follow these recommendations.

Another study, conducted at 77 hospitals in China, with the character of a national cross-sectional study with a certified cluster sample of patients, showed a multivariate regression analysis in 2014-2015 where the strongest predictor of patients' responsibility to healthcare providers was patient's trust and then the level of the patient's education. Acquaintances with healthcare providers and the frequency of hospitalizations in the past have had a reciprocal relationship with patients's sense of responsibility to healthcare providers [2].

It is also important to keep in mind that there is a problem with the use of Internet resources, namely that people are increasingly using the Internet resources to access the healthcare industry and related information, which is often incorrect or misleading the internet user $[3,4]$.

Some scientists state that patients should have responsibilities that include respect and gratitude to the doctor $[5,6,7,8]$. However, empirical evidence indicates that patients have limited feelings of responsibility to physicians. 
At the same time, it is necessary to understand which patients are most important to have a responsible attitude to themselves, their disease and treatment. In our opinion, these are patients with chronic and/or comorbid pathology. According to modern statistics, bronchial asthma (BA) is one of the leading problems in primary care medicine $[9,10]$. It is not news that these patients should constantly follow maintenance therapy, which includes basic treatment and a specific lifestyle. However, it has been found that patients with asthma who have comorbid pathology in the form of excess body weight (EBW) or obesity have a more severe disease course and have a low control of the disease course $[11,12,13]$.

\section{THE AIM}

The aim encouraging the patient to develop responsibility for the course of asthma against the background of EBW or obesity and introducing this program into the practice of family physicians.

\section{MATERIALS AND METHODS}

The study was conducted on the basis of the Department of Family Medicine and General Practice of Odessa National Medical University. By design, the study included 75 patients with asthma with varying degrees of severity, persistent course in the remission stage against the background of EBW or obesity. According to the randomization method, the patients were divided into 3 groups: the main group - 30 patients (the use of medication), the comparison group - 30 patients (training in the "Asthma School"), the $3^{\text {rd }}$ group was controls of 15 patients (basic therapy), from the main group Stage 1 according to the same inclusion / exclusion criteria to complete the clinical trial, namely to improve the drug treatment against the background of basic treatment with the use of bacterial lysate and inosine pronabex drugs, together with training at the Asthma School.

The Asthma School training program included: a series of theoretical and practical classes where the patients received theoretical and practical skills in diet therapy, breathing and therapeutic exercises against the background of standard basic therapy.

The developed program of classes included 5 group and 9 individual classes. The following issues were considered during group classes: 1) The concept of asthma, anatomy and physiology of the respiratory system;2) basic therapy of asthma; 3) the role of inhaled corticosteroids in the treatment of asthma; 4) exacerbation of asthma and its therapy. Night asthma; 5) non-medication methods of asthma treatment.

Individual classes included recommendations on: diet therapy, breathing exercises, therapeutic exercises.

Together with the Asthma School study, the patients in the main and comparison groups received self-monitoring diaries, which they filled in at home daily and brought to revisits to the doctor. The diary looked like tables where patients had to note the intake of medications, the implementation of breathing exercises, the frequency of taking rescue medications, waking up at night because of attacks of asthma, limitation of physical activity due to asthma. Each sheet also had the telephone number of the doctor who supervised the patient while studying at the Asthma School.

The control of the patient's disease and responsibility was performed according to the following criteria: understanding of the nature of the disease, methods of control and treatment of asthma, technique of using inhaler devices for drug delivery, adherence to the basic treatment, number of taking rescue drugs, namely short-acting $\beta$-2-agonists (SABA), decrease in BMI, controlled by bioempidansometry and weigh-scales -by OMRON BF 51 impedance meter and, most importantly, improvement in asthma control, by the Asthma Control Test (Quality Metri c Incorporated, 2002).

Statistical processing of the results was performed using parametric and non-parametric analysis methods. In the comparative analysis of independent groups, we used the Student's criterion for unpaired samples (subject to homoskedasticity and normal data distribution) and the Mann-Whitney test (for heteroscedastic data with a different type of distribution).

Sign correlation was studied by Spearman's $(r)$ correlation analysis, and Pearson's criterion $\chi^{2}$ was used to evaluate the relationship between qualitative and quantitative signs.

Patients' participation in this study was based on the written consent. There were used only medicines and licensed techniques registered in Ukraine. The study was conducted to preserve the confidentiality of personal information about patients.

\section{RESULTS}

According to the anthropometric study, 75 patients enrolled in the study were found to have EBW or obesity and the mean BMI was $31.67 \pm 0.53 \mathrm{~kg} / \mathrm{m}^{2}$. The patients had varying degrees of asthma severity, 15 patients with a mild degree, 35 with a moderate degree, and 25 - with severe BA. Most of them were women, namely 40 and 35 men. A Spearman correlation coefficient of $\rho=0.376$ was established, between the severity of the course and sex of the patients, the relationship between the studied signs was direct, and the closeness (constraint) force by the Cheddock scale was moderate.

The mean age of the patients was $43.93 \pm 1.15$ years. When conducting a correlation analysis between the age and severity of asthma it was found that the correlation coefficient according to Spearman was $\rho=0.541$, the relationship between the studied signs - direct, closeness (constraint) force by the Cheddock scale was noticeable.

Respiratory exercises were performed by 14 (46.67\%) patients in the main group and $16(53.33 \%)$ patients in the comparison group, but only in the primary diagnosis of asthma, at the time of the study, no patient practiced breathing exercises. 
Table I. Frequency of taking rescue medications per week in patients with bronchial asthma against the background of excess body weight or obesity in the course of application of the treatment-and-prophylactic complex

\begin{tabular}{ccc}
\hline Group & Follow-up period & The number of taking SABA per week \\
\hline \multirow{2}{*}{ Main group } & Before & $7 \pm 1.2$ \\
\cline { 2 - 3 } & After & $2 \pm 0.5^{*}$ \\
\hline \multirow{2}{*}{ Comparison group } & Before & $7 \pm 1.5$ \\
\cline { 2 - 3 } & After & $4 \pm 1.9$ \\
\hline \multirow{2}{*}{ Control group } & Before & $6 \pm 1.5$ \\
\hline & After & $6 \pm 1.2$ \\
\hline
\end{tabular}

Note: *p before-after $<0.001$

Table II. Body mass index and body component indices in patients with bronchial asthma against the background of EBW or obesity

\begin{tabular}{cccc}
\hline Index & Catamnesis stage & Main & Comparison \\
\hline \multirow{2}{*}{$\begin{array}{c}\text { IMT } \\
\mathrm{kg} / \mathrm{m}^{2}\end{array}$} & Before using TPC & $32.00 \pm 0.85$ & $31.88 \pm 0.87$ \\
\cline { 2 - 4 } & In 32 weeks after using TPC & $29.7 \pm 0.74^{*}$ & $29.8 \pm 0.73$ \\
\hline \multirow{2}{*}{$\% f a t$} & Before using TPC & $38.68 \pm 1.40$ & $39.20 \pm 1.30$ \\
\cline { 2 - 4 } & In 32 weeks after using TPC & $36.51 \pm 1.26$ & $36.59 \pm 1.28$ \\
\hline \multirow{2}{*}{ Visceral fat } & Before using TPC & $12.33 \pm 0.76$ & $11.93 \pm 0.83$ \\
\cline { 2 - 4 } & In 32 weeks after using TPC & $11.39 \pm 0.57$ & $11.41 \pm 0.71$ \\
\hline
\end{tabular}

Note: *p before-after $<0.05$

It was also found that $20(66.67 \%)$ patients in the main group and $21(70.00 \%)$ patients in the comparison group did not regularly use basic therapy and cancelled or changed the drugs without permission. However, it was found that the vast majority of patients, namely $42(70.00 \%)$ of both groups, did not follow the correct technique of inhalation drug delivery.

At the beginning of the study, $21(70.00 \%)$ patients in the main group and $15(50 \%)$ patients in the comparison group indicated that they did not have sufficient knowledge and motivation to keep the prescribed treatment. However, after the use of the medication, $26(86.67 \%)$ patients in the main group and $24(80.00 \%)$ patients in the comparison group noted that they had improved knowledge of asthma, treatment and asthma control. At the same time, $90 \%$ of the patients in the main group and the comparison group $(\mathrm{n}=54)$, after having motivational interviews, filling in the diary, achieving compliance with the doctor, acknowledged that greater responsibility for the control of the disease and adherence to administration rests on their shoulders.

In our country, there is a widespread practice of prescribing and using rescue drugs SABA as a monotherapy for BA, which by the principles of evidence-based medicine is absolutely irrational and has a negative impact on the course and control of the disease. The same trend was observed in our patients. After the Asthma School classes, the patients significantly reduced their use of SABA (Table I), which indicated a more conscious attitude toward basic therapy and improved compliance, which in turn indicated an increased sense of responsibility in this group of patients.

Another urgent issue that was solved at the individual class was teaching the patient how to use the inhalation device correctly. So, we have found that only 25 (33.33\%) of
75 patients enrolled in the study were able to use inhalation drug delivery device properly. Also, most patients did not know that there were different means of delivery of inhalation drugs, so we were individually selected inhalation drugs according to the international recommendations and wishes of the patient and selected a separate individual class in which the patient together with the doctor studied the stages of inhaler use. After the training, 45 patients $(76.66 \%)$ of the total patients of the main group and the comparison group began to perform respiratory movements with the inhalation device correctly.

During the follow-up period, positive dynamics of BMI reduction, percentage of the adipose tissue and visceral fat were observed in the patients who were trained in the Asthma School (comparison group) and in the patients treated with the developed TPC (Table II).

The table II shows that patients in the main group reduced body weight on an average by $4.5 \mathrm{~kg}$, and BMI from $32.00 \mathrm{~kg} / \mathrm{m}^{2}$ changed to $29.7 \mathrm{~kg} / \mathrm{m}^{2}(\mathrm{p}<0.05)$, although they did not reach $25.0 \mathrm{~kg} / \mathrm{m}^{2}$ of the target level because the follow-up period was not long. The patients in the comparison group also had a positive result, namely a decrease in the body weight on an average by $2.5 \mathrm{~kg}$ during the follow-up period and reduced BMI from $31.32 \mathrm{~kg} / \mathrm{m}^{2}$ to $29.8 \mathrm{~kg} / \mathrm{m}^{2}$ ( $\left.\mathrm{p}>0.05\right)$, although it was not as reliable as in the main group. The patients in the control group had no changes in BMI and even a small number of patients, namely 3 patients (20\%) increased their body weight by $1.9 \pm 0.9 \mathrm{~kg}$ for 32 weeks of the follow-up.

We noted a tendency for a decrease in the body weight and visceral fat in the patients of the main group and the comparison group, but these changes were not statistically significant $(\mathrm{p}>0.05)$. 
Table III. The number of steps per day in the dynamics of following-up patients with bronchial asthma against the background of EBW or obesity

\begin{tabular}{ccc}
\hline Groups & $\begin{array}{c}\text { Before using TPC } \\
\text { pressure/day }\end{array}$ & In 32 weeks after using TPC pressure/day \\
\hline Main & $1.800 \pm 0.17$ & $7.600 \pm 0.22^{*}$ \\
\hline Comparison & $1.930 \pm 0.16$ & $5.900 \pm 0.31^{*}$ \\
\hline Control & $1.870 \pm 0.26$ & $2.100 \pm 0.52$ \\
\hline
\end{tabular}

Note: *p before-after $<0.001$

Table IV. Changes in the result of the AST-test according to the severity of the course in patients with bronchial asthma against the background of EBW or obesity in the course of application of the treatment-and-prophylactic complex

\begin{tabular}{cccc}
\hline Group & Degree of severity & Before using TPC & In 20 weeks after using TPC \\
\hline \multirow{2}{*}{ Mai group } & Mild & $16.54 \pm 0.49$ & $20.16 \pm 0.75^{*}$ \\
\cline { 2 - 4 } & Moderate & $13.97 \pm 0.64$ & $17.08 \pm 0.52^{*}$ \\
\cline { 2 - 4 } & Severe & $11.88 \pm 0.34$ & $16.16 \pm 0.98^{*}$ \\
\hline \multirow{2}{*}{ Comparison group } & Mild & $16.61 \pm 0.53$ & $17.98 \pm 1.01$ \\
\cline { 2 - 4 } & Moderate & $14.01 \pm 0.97$ & $15.45 \pm 0.34$ \\
\hline \multirow{nyy}{*}{ Control group } & Severe & $11.75 \pm 0.81$ & $12.88 \pm 0.77$ \\
\cline { 2 - 4 } & Mild & $16.52 \pm 0.38$ & $16.66 \pm 0.67$ \\
\cline { 2 - 4 } & Moderate & $13.99 \pm 0.76$ & $14.01 \pm 0.45$ \\
\hline
\end{tabular}

Note: * ${ }^{*}$ before-after $<0.05$

It is well known that controlled dosed physical activity (CDPA) has a positive effect on asthma. Our patients were aware of this but did not follow this postulate. While analysing physical activity it was found that none of the patient visited the sports sections or the gym, sometimes physical exercises were performed at home by $23.33 \%(n=14)$ of the patients of the main group and the comparison group. According to the pedometer, at the beginning of our study, the majority of patients, namely 54 (72\%), took no more than 2 thousand steps per day. At the group and individual classes, recommendations were given to increase CDPA, in the form of short-term and clear goals. The results of the follow-up are shown in the table III.

The table III shows the positive dynamics in increasing the physical activity of the patients in the main group and the comparison group, but it was noted that the patients in the comparison group took less steps per day than patients in the main group, which was associated with deterioration of health, so we chose the tactics maintaining the results obtained, rather than increasing them, for the period until the patients' well-being was stabilized, with further prolongation of CDPA.

It should be noted that a decrease in BMI and an increase in CDPA were due to a more honest attitude of the patients on their health and lifestyle, indicating an increased sense of responsibility in the patients included in our study.

To assess disease course control, we selected a simple and rapid test to evaluate the disease course over the last 4 weeks, namely the AST test. The patients filled in the printed questionnaires together with the physician on their first visit, 20 weeks after TPC and 32 weeks after TPC. The results in the Table 4 reflect the average AST test according to the severity of BA in the three study groups.

The table IV shows that only patients in the main group had significant positive changes in asthma control, the patients in the comparison group also had positive dynamics, but it did not show statistically significant differences. In the control group, they did not differ during the follow-up period and had approximately stable AST test results. In the questionnaire survey at the last visit, which was in 32 weeks after the end of TPC, it was found that about $20 \%$ of the patients in the main and comparison groups reported a slight regression in wellness and in asthma control, respectively.

The obtained positive dynamics according to the long-term results over 32 weeks of the follow-up proved the effectiveness of the proposed program in improving asthma control in patients in the main group $R R=0.38$; $\mathrm{RRR}=0.62$, NNT $=2.12$; the patients in the comparison group had the following indices $-\mathrm{RR}=0.89$; $R R R=0.11$; $\mathrm{NNT}=4.05$. However, it should be noted that $90 \%$ of the patients noted an increase in responsibility for their health, course and asthma control, which is very important in the physician-patient relationship in today's world.

\section{DISCUSSION}

In our article, the topic was fully disclosed. The results of the research work are original, since in the literature of Ukraine this topic is not disclosed. It is necessary to introduce this technique into the practice of doctors, not only in the treatment of bronchial asthma, but also in the treatment of other chronic diseases. This article may be a prototype for research in other medical specialties. 


\section{CONCLUSIONS}

1. The patient's low educational attainment regarding the course, control and treatment of the disease is one of the problems in achieving physician-patient compliance on the path to asthma control.

2. The use of rescue drugs is irrational among the asthmatic population in Ukraine, which can be solved by raising awareness and responsibility for the disease and methods of treatment of asthma.

3. Responsible attitude of the patient to nutrition, controlled dosed physical activity influences the decrease in the body weight $(\mathrm{p}<0.05)$ and improves the patient's health, which is one of the key points in the improvement of asthma control.

4. Self-completion of the patient's diaries disciplines the patient and makes his / her attitude to BA and disease control more responsible in $90 \%$ of cases, which is confirmed in our investigated improvements in the AST test results $(\mathrm{p}<0.05)$.

5. Studying at the Asthma School together with pharmacological correction has a positive effect on the course of asthma and its control $(\mathrm{RR}=0.38 ; \mathrm{RRR}=0.62$, NNT $=2.12$ ).

6. The doctor should be interested in the fact that at the first and subsequent visits regarding the disease, in our case it is bronchial asthma, the patient will feel responsible for the disease. Therefore, when communicating with the patient, the physician should focus on this, provide the most complete answers to the patient's questions, provide educational literature and, if necessary, diaries of self-control.

\section{REFERENCES}

1. Arekapudi S. A Responsible Patient The author provides of an overview of patient responsibilities and discusses the move away from the paternalistic style of physician care. Virtual Mentor. 2003;5(4).doi: 10.1001/virtualmentor.2003.5.4.pfor1-0304

2. Ye $B$, Wang $X$, Wang F et al. Patients'sense of responsibility to healthcare providers and its predictors: A national cross-sectional survey in China. PLoS One. 2018; 13:12. doi: 10.1371/journal.pone.0207361.

3. Stevenson FA, Kerr C, Murray E, Nazareth I. Information from the Internet and the doctor-patient relationship: the patient perspective qualitative study. BMC Fam Pract. 2007;8:47. doi:10.1186/1471-2296-8-47.

4. Hu XM. Analysis of moral deficiency of false medical information. Hygienic soft science. 2008;22(3):207-209.

5. Maier B, Shibles WA. The philosophy and practice of medicine and bioethics. Springer Netherlands. 2011; 306(8):882.

6. Schmidt H. Patients' charters and health responsibilities. BMJ. 2007; 335(7631):1187-1189. doi: 10.1136/bmj.39387.393160.AD
7. Giordano J. The Good Patient: Responsibilities and obligations of the patient-physician relationship. Prac Pain Manag. 2007; 7(9):58-65.

8. Buetow $S$. Why patients have a moral obligation to give care to clinicians. J Eval Clin Pract. 2014; 20(6):890-895.

9. Global Asthma Report 2018. Auckland, New Zealand: Global Asthma Network, 2018. http://www.globalasthmanetwork.org/

10. World Health Organization. Health statistics and information systems. http://www.who.int/healthinfo/global_burden_disease/metrics_ daly/en/

11. Solovieva I, Sobko E, Demko I, Kraposhina A. Bronchial asthma and obesity. Therapeutic Archives. 2017; 89 (3):116-120.

12. Ignacio RMC, Kim Cheol-Su, Kim Soo-Ki Immunological Profiling of Obesity. J Lifestyle Med. 2014; 4(1)1-7.

13. Marko M, Pawliczak R. Obesity and asthma: risk, control and treatment. Postepy Dermatol Alergol. 2018;35(6):563-571.

The material of the article is a fragment of the research work of the Ministry of Health of Ukraine and the Department of Family Medicine and General Practice of Odessa National Medical University "Age-specific features of treatment and rehabilitation of pulmonary, endocrinological diseases in patients with overweight in the practice of family doctor" (№ state registration 0115U006645).

\section{ORCID and contributionship:}

Valentyna I. Velychko - 0000-0002-1936-3421 ${ }^{F}$

Yaroslava I. Venher - 0000-0002-1314-4850 ${ }^{\circ}$

Daria O. Lahoda - 0000-0003-0783-6225 A,B,C,D,E,F

\section{Conflict of interest:}

The Authors declare no conflict of interest.

\section{CORRESPONDING AUTHOR}

Daria 0. Lahoda

Odesa National Medical University.

Bazarnaia str. 19 f.10 Odesa Ukraine 65000

tel: +380966419743

e-mail: dlagoda19@gmail.com

Received: 17.01 .2020

Accepted: 05.03.2020

A - Work concept and design, B - Data collection and analysis, C - Responsibility for statistical analysis, D-Writing the article, $\mathbf{E}$-Critical review, $\mathbf{F}$ - Final approval of the article 